\title{
Prevalence, Contributing Factors and Management Strategies (Self-Management Education) of Type 2 Diabetes Patients in Nigeria: A Review
}

\author{
Emos E Tella ${ }^{1}$, Ismaeel Yunusa ${ }^{2}$, Judith H Hassan ${ }^{3}$, Ibrahim A Chindo ${ }^{4}$ and Victor B Oti ${ }^{5^{*}}$ \\ ${ }^{1}$ Department of Health Planning, Research and Statistics, Kaduna State Ministry of Health, Nigeria \\ ${ }^{2}$ College of Pharmacy, University of South Carolina, Columbia SC, USA \\ ${ }^{3}$ Department of Hospital Services, Kaduna State Ministry of Health, Nigeria \\ ${ }^{4}$ Department of Biology, Federal College of Education, Okene, Kogi state, Nigeria \\ ${ }^{5}$ Department of Microbiology, Nasarawa State University, Keffi, Nigeria
}

*Corresponding author: Victor B Oti, Department of Microbiology, Nasarawa State University, Keffi, Nigeria

\begin{abstract}
Diabetes is one of the major causes of morbidity and premature mortality globally with over 371 million people worldwide and more than $80 \%$ of morbidity and mortality due to diabetes occurred in the low- and middle-income countries (LMICs) including Nigeria, which has the highest burden of diabetes in Africa. The high number of medical admissions and deaths $(15 \%$ and $22 \%)$ due to diabetes complications in Nigeria reflect the poor quality of care. Therefore, this review aims to discuss the prevalence, contributing factors and management strategies (SelfManagement Education) of type 2 diabetes (T2D) in Nigeria. The review was an informal, targeted literature review that utilised secondary data from global health, PubMed data bases, websites of international organisation and government ministries and books from the libraries and personal collections. The factors contributing to the prevalence of diabetes complications in Nigeria were identified and discoursed in this review. Effective and feasible strategies of Diabetes self-management education (DSME) identified to promote implementation in Nigeria include; community-based DSME, family-based DSME and health facility-based DSME. All the DSME strategies are required in Nigeria for effective diabetes care. This review successfully documented the prevalence, patient related factors contributing and management strategies (SelfManagement Education) of T2D complications/outcomes in Nigeria and thus, combination of the above strategies is recommended for effectively addressing the needs of diabetes patients in Nigeria.
\end{abstract}

\section{Keywords}

Type 2 diabetes, T2D, Self-management education, DSME, Diabetes education, Nigeria

\section{Introduction}

Diabetes mellitus (DM) is known as a chronic metabolic disease of human characterized by hyperglycaemia which results from defects in insulin secretion, insulin action or both [1]. Diabetes is one of the major causes of morbidity and premature mortality worldwide; presently, affecting above 371 million persons globally and the estimation is projected to increase to 552 million in 2030 [2,3]. In 2012, about 4.8 million persons died due to diabetes globally and diabetes is predicted to be the $7^{\text {th }}$ leading cause of mortality worldwide in 2030 [3,4]. Above $80 \%$ of reported disease and death from diabetes occurred in low-and middle-income countries (LMICs) [5]. Nigeria has the highest burden of the disease in Africa, with about 1.7 million individuals living with type 2 diabetes (T2D) in 2006 with this count projected to rise to 4.8 million by 2030 [6].

Diabetes lowers the quality and life expectancy of the affected person due to its chronic nature and associated complications [7]. It can result in serious

Citation: Tella EE, Yunusa I, Hassan JH, Chindo IA, Oti VB (2021) Prevalence, Contributing Factors and Management Strategies (Self-Management Education) of Type 2 Diabetes Patients in Nigeria: A Review. Int J Diabetes Clin Res 8:148. doi.org/10.23937/2377-3634/1410148

Accepted: September 15, 2021: Published: September 17, 2021

Copyright: (C) 2021 Tella EE, et al. This is an open-access article distributed under the terms of the Creative Commons Attribution License, which permits unrestricted use, distribution, and reproduction in any medium, provided the original author and source are credited. 
long-term complications such as renal failure, blindness and amputation; furthermore, it is associated with heightened morbidity from cardiovascular disease, including myocardial infarction and stroke [8]. About $65 \%$ of diabetes death is due to cardiovascular complications, and $2 / 3$ diabetes patients will die of cardiovascular complications in industrialized regions [9]. In addition to the health-related burden, diabetes is linked to substantial economic burden on the National Health System (NHS), patients and the family $[7,10]$. For example, diabetes-related cost to the NHS in 2002 in the United Kingdom was 1.3 billion pounds, with most of the cost arising from diabetic complications [11].

In Nigeria and Africa at large, infection and acute metabolic complications have been reported to be the most common causes of death in DM patients [12]. In Sub-Sahara Africa (SSA), diabetic retinopathy is the key cause of adult blindness; with diabetes being 6 times more prone to cataract and 1.4 times more susceptible to open angle glaucoma compared to non-diabetics [13]. Suddenly, developing countries including Nigeria are now experiencing a double burden of communicable and non-communicable diseases [14,15]. In 2006, a hospital study by Ogbera, et al. [16] reported that diabetes accounted for $15 \%$ of all admissions and $22 \%$ of all medical deaths in Nigeria; and that death from acute metabolic hyperglycaemic emergency was $46 \%$, diabetic foot $(30 \%)$, cardiovascular and renal complications accounted for $16 \%$ and $3 \%$ respectively [16].

Worldwide, T2D has affected above $90 \%$ of diabetes and the prevalence is still rising in every country $[3,4]$. The global prevalence in 2012 was $8.3 \%$; with Africa having the highest percentage of undiagnosed diabetes cases $(81.3 \%)$ in 2012 [4]. It is projected that the percentage of diabetes cases in SSA will rise by $98 \%$ from 12.1 million to 23.9 million in 2030 . The frequency of diabetes in Nigeria as at 2012 was 4.83\% [4], this percentage has more than doubled from the previous $2.2 \%$ prevalence from the NHS in 1997 [2].

Diabetes self-management education (DSME) has since been identified as the bedrock for diabetes care, irrespective of the treatment strategy adopted [17]. DSME and medical therapy that result in strict glycaemic control has been reported to delay the onset of, or decrease complications of diabetes by $50-75 \%$ among diabetes patients [18]. DSME programme was reported to decrease drugs cost by $62 \%$, and $38 \%$ of diabetes-related cost in 10 Latin American countries and Argentina respectively; and the cost of the programme was reported to be reduced [7]. This review looked at the prevalence, contributing factors and management strategies (Self-Management Education) for T2D patients in Nigeria.

\section{Methodology}

\section{Study design}

This review was an informal, targeted literature review conducted without an a-priori protocol following standard systematic literature review standards. The targeted review was preferred, because it allows for detailed examination of subject from different perspective and context, thereby enhancing the critical analysis of the risk factors of T2D complications, and the most effective and feasible strategies to promote DSME in order to prevent and control diabetes complications in Nigeria.

\section{Search strategy}

Some electronic databases for the literature search were used in this targeted review which include; Global health, Medline, PubMed, Pop line, Web of science and Cochrane, WHO Library in Geneva, University of Leeds Library and personal collections based on the following sets of keywords: Type 2 diabetes, Prevalence, Patient factor, Adult-onset diabetes, Insulin resistant diabetes, self-management, self-care, patient educat ${ }^{*}$, primary prevention, program*, intervene*, strategy*, family-based, community-bases, PHCs, effective, costeffectiveness, risk factors, complications, Nigeria, subSaharan Africa, Developing countries.

\section{Selection criteria}

Both qualitative and quantitative articles including randomized controlled trials (RCTs) published in English with free full text access during the last 15 years between 1st January 1999 and $31^{\text {st }}$ December 2013, which focus on prevalence, patient/therapy factors and self-management education for T2D patients in Nigeria, were included in this review. Studies from other languages that do not report T2D and not in full access, and also more than 15 years (outside the duration of the review) were excluded.

\section{Literature Review}

\section{Prevalence of type 2 diabetes in Nigeria}

The prevalence of diabetes is grossly underreported in Africa including Nigeria [14]. In 2012, about 4.8 million persons died due to diabetes globally and diabetes is predicted to be the 7th leading cause of mortality worldwide in 2030 [3,4]. Above $80 \%$ of diabetes cases were undiagnosed in Africa as at 2012 [4]; however, evidence emerging from the available literatures depicts that diabetes in Nigeria is pictured as a major public health problem with a steady rise in prevalence [19]. A population-based study in the late eighties finds a prevalence of $1.7 \%$ and $1.4 \%$ in the urban and rural settings respectively [20]. A NHS in 1997 reported a diabetes prevalence of $2.2 \%$ with a male to female ratio of $1: 1.1$ [2].

Distribution of type 2 diabetes by Gender and Place of residence in Nigeria: Studies in some parts of Nigeria has shown a higher prevalence of type 2 diabetes in females compared to males which is attributed to both 


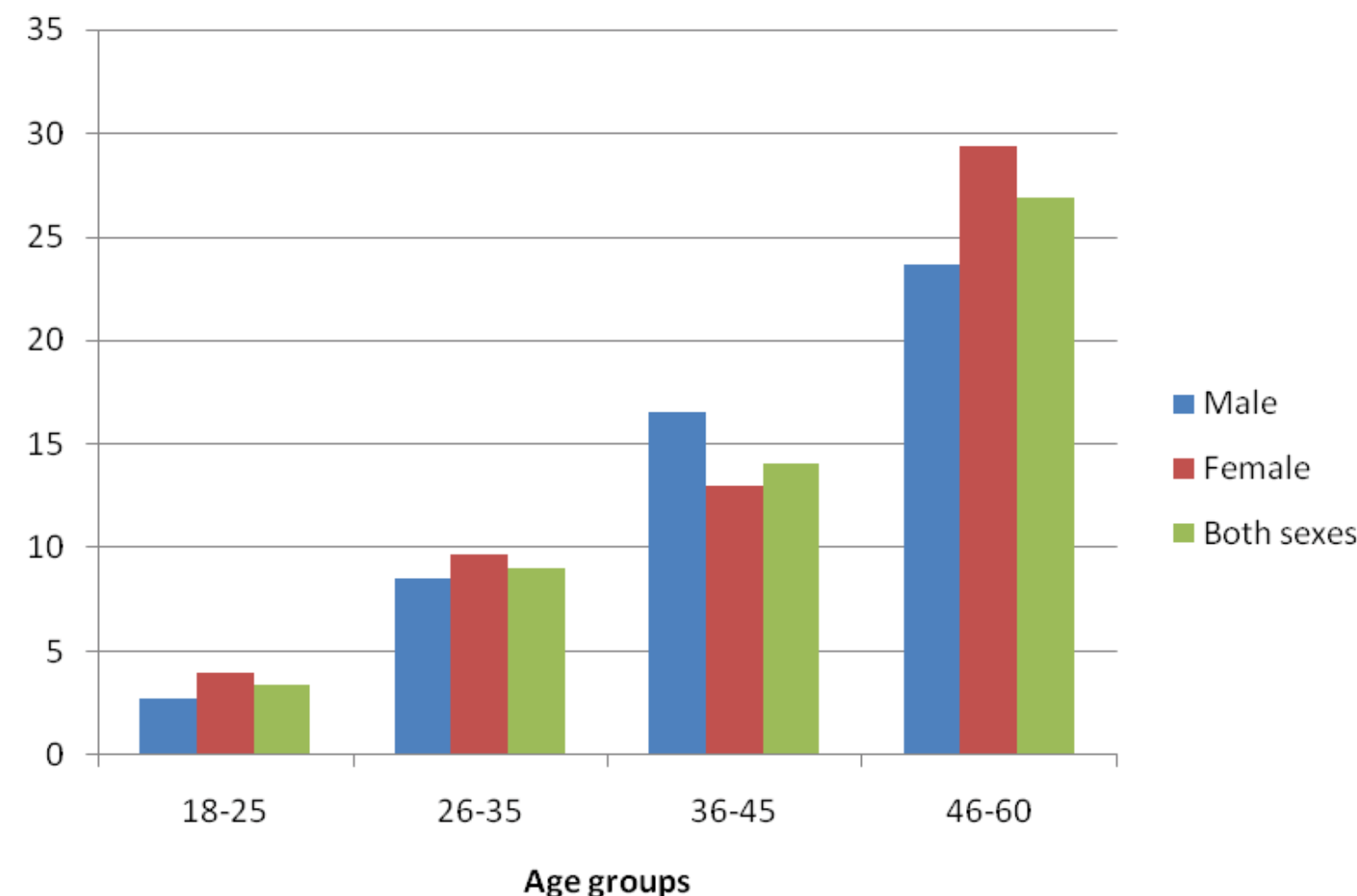

Figure 1: Percentage of diabetic adults in Uyo, South-South Nigeria based on age and gender [19].

biological and psychosocial predictors. Most women with T2D are often associated with more complications such as coronary heart disease [19]. Figure 1 depicts the percentage of type 2 diabetic adults by gender and age group using Uyo, South-South, Nigeria as a case study. From the Figure 1, the prevalence of type 2 diabetes rises proportionately with age in both sexes; the prevalence is highest among the age groups of 46-60 years and lowest among the age groups of $18-25$ years in both sexes. Above $95 \%$ of diagnosed diabetes cases in Nigeria are T2D [21,22].

\section{Contributing factors to diabetes complications in Nigeria}

The main factors contributing to the burden of T2D and its associated complications on the patients and the healthcare system in Nigeria are reported below.

\section{Patient related factors}

Knowledge and awareness: Researches from different parts of Nigeria shows that T2D patients have sub-optimal knowledge on diabetes complications, risk factors, duration of anti-diabetic treatments, foot-care, Self-monitoring of blood glucose (SMBG), and symptoms of hypoglycaemia/hyperglycaemia [23]. A hospitalbased study among diabetes patients in the South-west of Nigeria showed that poor adherence to diabetic medications is basically caused due to poor knowledge and practice of diabetic self-management [23]. In South-eastern Nigeria, about $60 \%$ of diabetes patients were not aware of the causes of T2D in a hospital-based study, more than two-thirds of the patients did not know about self-monitoring of blood glucose (SMBG), $17.4 \%$ and $40 \%$ of the patients were not aware of the relevance of moderate exercise and for how long they were to take their medications respectively [24].

Desalu, et al. [25] in a multi-centre study in Nigeria, reported that about $75 \%$ of diabetes patients were not aware of the danger of smoking, $50.6 \%$ of the importance of foot wear inspection and $61.4 \%$ of regular inspections of feet, while $69 \%$ of the patients were unaware of the need to see their health care providers whenever they have blisters or bleeding between their toes.

Affordability of diabetes care: Healthcare in Nigeria is out of pocket payments, because the government provide only about $25 \%$ of the health care expenditure including diabetes care [21]. Furthermore, diabetes patients pay about $75 \%$ of the health care cost which include medicines, laboratory services, hospitalisation, and transportations without reimbursement [21]. Furthermore, above $90 \%$ of Nigerians including diabetes patients live below poverty level of 2 US dollars per day; therefore, accessing healthcare in Nigeria is a challenge for diabetes patients [21]. In Ghana, a qualitative study on diabetes patients considered biomedical care as ideal, but due to non-affordability of diabetes medicines, the patients avoid medical therapy and seek treatment from traditional healers which resulted in diabetes complications [21].

In addition to patients paying for their healthcare cost, diabetes drugs are being sold at prices far higher 
than the cost of these drugs in other parts of the world [21]. For example, Glibenclamide, an oral hypoglycaemic agent used in the treatment of T2D was found to cost more than 17 times the international price in public health facilities [26].

Worry to note is that poor individuals including the Nigerians poor are more likely to develop chronic illnesses, suffer complications and die from chronic illnesses including diabetes [27]. This is because poor people are more likely to have financial deprivation, develop psychosocial stress, unhealthy living conditions and have poor access to quality health care [27].

Lack of psychosocial support: Depression is a common characteristic among diabetes patients in Nigeria; and it is associated with poor glycaemic control and diabetes complications [28]. Depression in diabetes patients is associated with glucose dysregulation, physical inactivity, therapy non-compliance, substance abuse, smoking and weight gain that could lead to poor glycaemic control and diabetes complications [28].

Agbir, et al. [28] in a hospital-based study, found that depression is more in women with diabetes when compared to their male counterpart with a female to male ratio of $3: 1$, and that about $48.4 \%$ of diabetic patients with depression reported with at least one form of complications like cataract, renal problems, foot ulcers and erectile dysfunction as compared to $20.9 \%$ of non-depressed diabetics [28]. Most health care providers in Nigeria do not always look out for depression among diabetes patients, due to the busy schedule, lack of awareness and lack of high index of suspiciousness to look out for depression among diabetic patients [28].

Lifestyle and personal behaviour: Uncontrolled urbanization with associated changes in diets and life style reduced physical activities as a result of improved standard of living; have led to a significant rise in the incidence of obesity in developing nations including Nigeria [29]. This has resulted to rise in prevalence of T2D with an associated increase in diabetes complications [29].

A report from a hospital study in South-east Nigeria on factors responsible for non-adherence to anti-diabetic medications; shows that about $70 \%$ of non-adherence to medication was due to dose omission (behaviour) [24]. Some of the reasons for the dose omission were dissatisfaction of taken medications on daily basis and inconvenience of taken medications outside of home [24]. Also in Nigeria, most especially in the rural areas and the urban slum, some people including diabetic patients have the habit of walking bare footed. These patients are at high risk of developing foot complications from injuries and infections [30].

Culture and beliefs: Diabetes in Africa including Nigeria has been associated with myth, sorcery and witch craft
[2]. Some believe that diabetes is inherited from parents; others believe diabetes is curable and avoid medical treatment while seeking treatment from traditional healers, and others believe diabetic medications are not effective; all these factors contribute to poor glycaemic control and diabetes complications [24].

In most parts of Nigeria especially in the South-South and South-West, certain Christian religion (popularly known as white garment) encourages individuals including diabetes patients not to use footwear in their worship places (indoors or outdoors); which is a religious belief [30]. A situation that can lead to increased risk of infection from injuries, peripheral vascular disease, nerve damage and foot complications in diabetic patients [30].

\section{Therapy of Type 2 diabetes}

The hallmark of metabolic abnormality in T2D and its associated complications is hyperglycaemia [31]. Therefore, the overall goal of therapy is to relieve symptoms and to prevent onset of complications by targeting normal glycaemia [5]. The recommended glycaemic target by the American Diabetes Association (ADA) is to achieve and maintain the HbA1C levels of less than $7 \%$ [31].

The clinical management of T2D is hinged on an effective stepwise implementation of available therapeutic strategies, in which failure to achieve glycaemic control leads to the introduction of more intensive therapeutic strategies [32]. The IDF (2006, cited in DAN, 2011 p. 104) treatment guidelines for T2D recommended for SSA is given below:

Life style modification plus metformin and or thiazolidiones: Life style changes include diet and physical activity, smoking and alcohol cessation.

Oral combination therapy: Failure to achieve or sustain glycaemic goals, within 3 months of initiation of life style intervention, requires addition of oral combination therapy.

- Sulfonylureas and or meglitinide (For non-obese patients).

- Metformin and or thiazolidiones (For obese patients).

Start from the lowest dose and increase according to need until a maximum dose is reached. Add another class of oral agents if glycaemic control is not met after 3 months.

Oral combination therapy plus insulin: If oral combination therapy fails to achieve glycaemic control, basal insulin at bed time or intermediate insulin could be introduced after 3 months.

Insulin therapy: More than once daily insulin therapy is required, if oral combination therapy, plus insulin fail to control blood glucose level. 
Treatment of other risk factors: Adequate treatment of arterial hypertension, dyslipidaemia and prevention of thrombotic state, lowered the incidence of cardiovascular complications in T2D patients; thus, therapy of other risk factors complements the treatment of hyperglycaemia to enhance the quality of life and life expectancy of diabetes patients.

The main factors contributing to diabetes complications in Nigeria are patient factors. Therefore, DSME has been recognised as the bedrock of all diabetes care irrespective of the treatment plan $[33,34]$.

\section{Diabetes Self-Management Education (DSME)}

The major goals of Diabetes Self-Management Education (DSME) are to enhance metabolic control and quality of life, to halt diabetes related complications, while keeping cost acceptable $[33,35]$. DSME empowers individuals with diabetes to take charge of their own situation by making informed choices for self-directed behaviour change, which make them to integrate selfmanagement into their routine lives and ultimately to decrease diabetes- related complications and to optimise healthcare cost $[35,36]$. An empowered patient is the one who has the knowledge, skills, attitude and selfawareness necessary to influence their own behaviour and that of others to enhance their life qualities [36]. DSME accelerate self-efficacy among diabetes patients, which is one's belief in the capacity to perform a desired health outcome [37].

Findings from systematic review and meta-analyses, and randomised control trials (RCTs) of different studies support the effectiveness of DSME at enhancing self-care behaviours, improving glycaemic control, lowering health care cost and improving the quality of life of patients with T2D particularly in the short term [36,38,39].

Standard Principles of DSME: According to Clark [36], the principles of DSME include the following:

1. DSME is effective for improving clinical outcomes and quality of life, at least in the shortest-term.

2. DSME has evolved from primary didactic presentations to more theoretical based empowerment models.

3. There is no one best programme approach to DSME; however, programs incorporating behavioural reframing and psychological strategies demonstrate improved outcomes. Additional studies show culturally and ageappropriate programs improved outcomes and that group education is effective.

4. On-going support is critical to sustain progress made by participants during the DSME programme.

5. Behavioural goal-setting is an effective strategy to support self-management behaviours.

Components of DSME: The following according to Scain, et al. [32], are the components of DSME:

- Definition and meaning of diabetes

- Teaching of the risk factors, signs and symptoms of diabetes

- Education on signs, symptoms and management of hypoglycaemia

- Education on diet and physical activity

- Teaching on appropriate use of medications and SMBG technique

- Education on feet examination and care

- Screening awareness and prevention of shortand long-term complications

- When to refer patients for specialist care and to involve family members.

Outcome indicators of DSME: The outcome measures of DSME can be used by diabetes educators to evaluate the effectiveness of DSME programs by comparing patient's performance with the established benchmarks in order to determine the unique contributions of DSME in the overall context of diabetes care [40]. The ADA recommends the assessment of DSME outcome measures at least per year in order to guide and encourage continual education [33].

The summary of DSME outcome measures is found below (Table 1).

DSME-DSME delivery strategies: Apart from delivering DSME at the traditional clinical hospitals, DSME can also be delivered through the community, family and telemedicine to enhance diabetes-self management $[42,33]$.

Community-based DSME: Community-based DSME refers to DSME intervention offered at the community gathering places, such as; community centres, faithbased institutions, private facilities and schools $[43,44]$. Community-based DSME should not replace diabetes education delivered in the clinical settings $[10,42]$.

A low-cost community-based DSME programme was organised for uninsured Mexican Americans with diabetes in a community in Dallas, USA [10]. The diabetes educators were trained community health workers. Volunteer certified diabetes educators, dieticians and endocrinologist provided training for the community health workers on DSME, but had no direct contact with the patients [10]. The programme lasted for 12 months; and consists of three 60 minutes educational sessions and a quarterly assessment [10]. The programme focused on medication adherence, meal planning, SMGB, prevention of short- and long-term diabetes complications, smoking cessation and limited 
Table 1: Outcome measures for DSME $[33,41]$.

\begin{tabular}{|c|c|c|}
\hline Short-term outcomes & Intermediate (process) outcomes & Long-term outcomes \\
\hline $\begin{array}{l}\text { Glycaemic control } \\
\text { HbA1c } \\
\text { Blood glucose } \\
\text { Physiologic outcomes } \\
\text { Weight } \\
\text { Lipid profiles } \\
\text { Foot lesions } \\
\text { Blood pressure } \\
\text { Microalbuminuria } \\
\text { Retinopathy } \\
\text { Lifestyle } \\
\text { Physical activity } \\
\text { Diet } \\
\text { Smoking } \\
\text { Mental health outcomes } \\
\text { Depression } \\
\text { Anxiety } \\
\text { Work-related outcomes } \\
\text { Work days lost } \\
\text { Restricted duty days }\end{array}$ & $\begin{array}{l}\text { - } \quad \text { Knowledge } \\
\text { Skills } \\
\text { SMoblem-solving skills } \\
\text { Medication administration (including insulin) } \\
\text { Psychosocial outcomes } \\
\text { Self-efficacy } \\
\text { Health beliefs } \\
\text { Mood } \\
\text { Attitude } \\
\text { Coping skills } \\
\text { Self-assessed health status } \\
\text { Locus of control } \\
\text { Perceived barriers to adherence } \\
\text { Healthcare system outcomes } \\
\text { Regular source of care } \\
\text { Regular visits } \\
\text { Availability of patient's education } \\
\text { Medication adherence } \\
\text { Screening foot and eye exams } \\
\text { Monitoring of glycaemic control } \\
\text { Monitoring of CVD risk factors }\end{array}$ & $\begin{array}{l}\text { Macro vascular complications } \\
\text { Peripheral vascular disease } \\
\text { Coronary heart disease } \\
\text { Cerebrovascular disease } \\
\text { Micro vascular complications } \\
\text { Retinopathy } \\
\text { Nephropathy } \\
\text { Peripheral neuropathy } \\
\text { Periodontal disease } \\
\text { Foot lesion, amputations } \\
\text { Mortality } \\
\text { Quality of life } \\
\text { Disability/function } \\
\text { Economic outcomes } \\
\text { Outpatient utilisation } \\
\text { Hospitalization rates } \\
\text { Cost } \\
\text { Cost-effectiveness and cost } \\
\text { benefits }\end{array}$ \\
\hline
\end{tabular}

use of alcohol, $\mathrm{HbA1c}$ test, provision and use of diabetes education materials, reviewed of test results and what was thought during the educational sessions; and the findings reported to the participants physicians [10]. The programme significantly improved $\mathrm{HbA} 1 \mathrm{c}$ (mean $\mathrm{HbA} 1 \mathrm{c}$ from $8.22 \%$ to $7.0 \%$ ) among type 2 diabetes patients, who participated in the programme for 12 months [10]. More so, in San-Francisco, USA, a RCT of a peerled community-based DSME programme, developed based on need assessment for patients with T2D [45]. Most of the peer educators had type 2 diabetes, were selected from the same community as the participants, and were not health professionals but were trained by certified diabetes educators. Participants were asked to come along with their family members [45]. The programme lasted for 6 weeks with a weekly 2 hour 30 minutes interactive session which include role play and discussions; the content of the programme covers most areas of American Association of Diabetes Education curriculum with emphasis on promoting self-efficacy (action planning, goal setting and problem solving) among participants [45]. The peer-led community basedDSME significantly enhanced depression, symptoms of hypoglycaemia, healthy eating, patient-provider communication and self-efficacy among participants compare with the control, however, there was no significant improvement in HbA1c [45]. Communitybased DSME will increase coverage of diabetes care to areas without diabetes health services.

Community-based DSME can be delivered by trained nurses, community health workers, diabetic peers and lay people under the supervision and coordination of the patients' primary care providers [43]; therefore, operationally feasible in Nigeria. Studies have shown that well trained nurses, community health workers, diabetes peers and lay people from the community can be trained to effectively provide diabetes education $[10,18,46]$.

In Nigeria, the method of training-of-trainers using certified volunteer diabetes educators to provide standard DSME training to few health workers, who will in turn train others, in order to improved coverage and further minimise cost, can be applied. Training-oftrainers method has shown to be feasible in training diabetes educators in low-income settings [47]. Other additional requirements are; educational materials, glucose monitors, venue for the programmes [10,35].

Community-based DSME promote cultural relevance which increase programme acceptability, this is possible because the diverse learning styles of different cultures including diet, cultural beliefs and social emphasis are better addressed in the community settings [18,35]; therefore, community-based DSME will be acceptable in Nigeria. Also, the use of appropriate educational techniques may increase relevance and acceptability of 
community-based DSME [35]. Furthermore, recruiting diabetes educators from the community, who can speak the local dialect will further promotes acceptability of the programme $[10,18]$. Community-based DSME is organised based on patients' perceived problems and convenience, therefore promoting acceptability [44]. Community-based DSME also enhance equity and increase coverage of diabetes care, by reaching the medically underserved population, people who would not normally receive this education due to access barriers to health services and the poor people who cannot afford the cost of diabetes care [10,35]. Furthermore, community-based DSME may be convenient, especially for those in the rural settings and thus promotes attendance [35]. Community-based DSME organised in the church and mosque settings in Nigeria will reach more women and hence, addressed gender equity.

Community-based DSME can be planned at a low cost, depending on the resource capacity and the needs of the community [35]; therefore, communitybased education is a low-cost programme which can be afforded by low- and middle-income countries [10].

Family-based DSME: Family based DSME is any intervention that is delivered to an individual with T2D, and/or at least one other family member, with the aim of improving outcomes of patients with T2D [41]. The main objective of family-based intervention is to improve glycaemic control and to reduce diabetes related complications [41]. Therefore, DSME intervention has shift focus away from the patients with diabetes, with more focus on the family context of disease management [41].

Family members have a key influence on DSM, because most of the self-management behaviours such as; dietary requirements, exercise, emotional support, reminders for taking medication and checking of blood glucose of diabetic patients usually take place within the family, hence require family support [41]. Therefore, the illness perception of the family members of a diabetic patient influences the types of health-related behaviours and coping mechanism of diabetes patients with either a positive or negative health outcome [41]. Also, diabetes and its management impact heavily on the daily life of family members of diabetic patients $[41,48]$. "The Family is the life context that is the most pervasive, has the greatest most-lasting effect on its members, and has the highest influence on the management of T2D" [41].

There is enough literature from systematic reviews on the effectiveness of family-based intervention in improving the health outcome of patients with type 1 diabetes (T1D) and other chronic illnesses such as hypertension and myocardial infarction $[41,49,50]$. However, only few studies exist on the effectiveness of family-based DSME in improving T2D care [48-50]. For example, the peer-led community programme in section 5.4.1. (Standard Principles of DSME) above is also a family-based DSME, since the patient's family members also attended the programme and it was effective. Studies have also shown that with spouse involvement in self-management of diabetes, women show significant improvement in their health [51]. This demonstrates the significance of providing women with diabetes socio-emotional support by their spouse. In Nigeria, mental health services are scarce, therefore family-based DSME will be relevant in teaching family members to provide psychological support to diabetes patients which will further improve diabetes care by reducing depression among diabetic patients. Familybased DSME in Nigeria is organisationally feasible because Nigerian lives in extended family structure; therefore, patients can easily invite their family members along for diabetes education.

Family-based DSME is culturally relevant and should be organised in the evenings or during the weekends, to enable family members attend [48]. Family based DSME will be financially feasible, since there will be only a little addition or no difference in the cost of the programme when compared with either community or Health facility-based programme.

Health facility-based DSME: Health facilitybased DSME is the provision of a structured diabetes educational programme to diabetes patients, at the Primary Health Care's (PHCs) and hospitals by trained nurses, physicians, dieticians or psychologists, in addition to the usual routine diabetes care [32,51]. Providing DSME in clinical settings will improve health professional knowledge and skills in diabetes management $[47,52]$.

In a community hospital in rural part of Taiwan, a group diabetes education programme organised for T2D in addition to the routine medical diabetes care [37]. The programme was delivered by trained nurses as diabetes educators, who provided a group diabetes educational session and a group discussion to promote self-efficacy among diabetes patients who participated in the programme. The diabetes education programme significantly improved the quality of life and $\mathrm{HbA1C}$ among participants (HbA1c 7.40\%) compare with the control (HbA1c 8.02\%) [37]. To improve the quality of diabetes care in Nigeria, diabetes care should be integrated with communicable disease services in all the health facilities; this will improve the supply of essential diabetes medicines, provision of diagnostic and diabetes monitoring equipment, training of health workers on diabetes care, proper distribution of diabetes treatment guidelines. Also, health workers salaries should be increase and rural allowance scheme be introduced.

Health facility based-DSME session is delivered to patients either individually or in groups [53]; research have shown that both methods are equally effective, however, group sessions are more cost-effective, give 
more patient satisfaction and interactive compared to one-on-one sessions and is therefore preferable [17]. Providing DSME in health facility where the usual diabetes care normally takes place is organisationally feasible, using trained nurses, dieticians, psychologists and physicians as diabetes educators [32]. In Nigeria, training-of-trainers can be used in training healthcare professionals in the provision of DSME in health facilities as above. However, enhancement of diabetes work force is fundamental to the success of health facility-based DSME in Nigeria, due to shortage of health workers. Patients' convenience should be taken into consideration when organising DSME at the health facility in order to encourage attendance and acceptability [50]. Provision of DSME in PHCs in Nigeria will increase coverage and improve quality of diabetes care, especially in rural areas; therefore, addressing the issue of inequity in terms of quality of diabetes care to an extent, since PHCs are the closest to the rural communities [54].

Telemedicine-based DSME: Telemedicine-based DSME is an alternative means of providing effective diabetes education through computers, mobile phones, and teleconference in settings with poor access to diabetes care such as; the medically underserved communities and the low-income patients who cannot afford diabetes care $[11,54]$. Telemedicine may be a promising way of providing quality diabetes care to those with access barriers and reduced cost $[55,56]$.

Evidence on the effectiveness of telemedicine based DSME is still emerging and has shown mixed outcomes, most of the studies conducted were small population research [11]. An automated telephone call with a telephone nurse follow-up programme organised for Mexican American with type 2 diabetes [56]. The automated calls are structured messages recorded in a human voice directed to the patients; the patients responded by interacting with the system using their touch-tone key pads [56]. The response is in the form of information about SMBG, foot problems, poor glycaemic control; and based on the patient report generated by the automated calls, a telephone nurse follow-up addressed the patient's problems through telephone calls and also provided additional self-care education to the patients. The follow-up nurse had no contact with the patients except the patients automated assessment reports and her previous telephone contact notes. Patients who participated in the programme achieved better glycaemic control, reported more frequent SMBG, foot inspection and fewer problems with medication adherence compare with the control (patients who received routine diabetes care) [56].

Computer based DSME are complex interventions requiring expertise, computer literate nurses, computer equipment's and good internet facilities to operate $[11,54,57]$; which are lacking in Nigeria, telemedicine- based DSME is not operationally feasible in Nigeria as at today. Majority of the rural areas in Nigeria where telemedicine will be more beneficial have no network coverage to operate mobile phones. Therefore, this is recommended to Federal and State Government to make provision for the betterment of their diabetes populace.

Telemedicine-DSME may be acceptable; using a diabetes educator who can communicate in local language [54]. However, diabetes patients living in areas without internet services cannot have access to such care. The cost of telemedicine DSME is very expensive $(\$ 8,000$ per person per year) compared to other DSME strategies with similar outcomes [55]. Nigeria is a developing country with the largest population in Africa (160 million), therefore the high cost of telemedicine can be a barrier for implementation. Also, more than $90 \%$ of Nigerians live below poverty level [7], therefore, a lot of Nigerians in rural areas cannot afford mobile phones which are the cheapest means of telemedicinebased DSME.

\section{Future Perspectives of DSME Programmes}

Several studies have emphasized the need for continued support and reinforcement of DSME programme, to ensure sustainability of DSME relatedhealth outcomes over a long period of time [33]. A lifelong management programme (LMP); which is a communitybased, patient-centered, long term self-management intervention, designed for DSME sustainability [17]. The programme aims at helping patients to sustain and improve on diabetes self-management gains achieved in the previous short term DSME programmes [17]. LMP has demonstrated to be effective in sustaining DSME health related outcomes among participants [17].

\section{Conclusion}

This review successfully documented the prevalence, patient related factors contributing and management strategies (Self-Management Education) of T2D complications/outcomes in Nigeria. The factors contributing to the prevalence of diabetes complications in Nigeria were identified and discoursed in this review. Effective and feasible strategies of Diabetes selfmanagement education (DSME) identified to promote implementation in Nigeria include; community-based DSME, family-based DSME and health facility-based DSME. All the DSME strategies are required in Nigeria for effective diabetes care. This review suggested that in order to maximise the impact of DSME in Nigeria, a combination of different DSME delivery strategies is the best approach; as no single delivery strategy of DSME can address the needs of diabetes patients in Nigeria.

\section{References}

1. American Diabetes Association (2011) Diagnosis and classification of diabetes mellitus. Diabetes Care 27: s5-s10. 
2. Oputa R, Chinenye S (2012) Diabetes mellitus: A global epidemic with potential solutions. African Journal of Diabetes Medicine 20: 33-35.

3. International Diabetes Federation (2011) Diabetes atlas. $\left(5^{\text {th }}\right.$ edn), International Diabetes Federation, Brussels, Belgium, 121-128.

4. International Diabetes Federation (2012) Diabetes atlas. ( $5^{\text {th }}$ edn), International Diabetes Federation, 2012 update. Brussels, Belgium, 121-128.

5. World Health Organizaiton (2013) Diabetes fact sheet.

6. World Health Organizaiton (2006) World Health Report, 2006. World Health Organization, Geneva, Switzerland.

7. Narayan KV, Zhang P, Kanaya AM, Williams DE, Engelgau MM, et al. (2006) Diabetes: The pandemic and potential solutions. Disease Control Priorities in Developing Countries, 591-603.

8. Davies MJ, Heller S, Skinner T, Campbell M, Carey M, et al. (2008) Effectiveness of the diabetes education and self management for ongoing and newly diagnosed (desmond) programme for people with newly diagnosed type 2 diabetes: Cluster randomised controlled trial. BMJ 336: 491-495.

9. Grundy SM, Benjamin LJ, Burke GL, Chait A, Eckel RH, et al. (1999) Diabetes and cardiovascular disease: A statement for healthcare professionals from the american heart association. Circulation 100: 1134-1146.

10. Culica D, Walton JW, Prezio EA (2007) CoDE: Community diabetes education for uninsured Mexican Americans. Proc (Bayl Univ Med Cent) 20: 111-117.

11. Pal K, Eastwood SV, Michie S, Farmer AJ, Barnard ML, et al. (2010) Computer-based diabetes self-management interventions for adults with type 2 diabetes mellitus. Cochrane Database Syst Rev 2013: CD008776.

12. Idemyor V (2010) Diabetes in sub-Saharan Africa: Health care perspectives, challenges, and the economic burden of disease. J Natl Med Assoc 102: 650-653.

13. Azevedo M, Alla S (2008) Diabetes in sub-saharan Africa: Kenya, Mali, Mozambique, Nigeria, South Africa and Zambia. Int J Diabetes Dev Ctries 28: 101-108.

14. Adibe M, Aguwa C, Ukwe C, Okonta J, Udeogaranya O (2009) Diabetes self-care knowledge among type 2 diabetic outpatients in South-Eastern Nigeria. Int J Drug Dev Res 1: 85-104.

15. Kengne AP, Amoah AG, Mbanya JC (2005) Cardiovascular complications of diabetes mellitus in sub-Saharan Africa. Circulation 112: 3592-3601.

16. Ogbera A, Chinenye S, Onyekwere A, Fasanmade O (2007) Prognostic indices of diabetes mortality. Ethn Dis 17: 721-725.

17. Tang TS, Funnell MM, Anderson RM (2006) Group education strategies for diabetes self-management. Diabetes Spectrum 19: 99-105.

18. Brown SA, Garcia AA, Kouzekanani K, Hanis CL (2002) Culturally competent diabetes self-management education for Mexican Americans: The starr county border health initiative. Diabetes Care 25: 259-268.

19. Ekpenyong CE, Akpan U, Ibu JO, Nyebuk DE (2012) Gender and age specific prevalence and associated risk factors of type 2 diabetes mellitus in Uyo metropolis, South eastern Nigeria. Diabetologia Croatica 41: 17-28.

20. Okoro E, Adejumo A, Oyejola B (2002) Diabetic care in
Nigeria: Report of a self-audit. J Diabetes Complications 16: 159-164.

21. Chinenye $S$, Uloko $A E$, Ogbera $A O$, Ofoegbu $E N$, Fasanmade OA, et al. (2012) Profile of Nigerians with diabetes mellitus-diabcare Nigeria study group (2008): Results of a multicenter study. Indian J Endocrinol Metab 16: $558-564$

22. Chinenye S, Ofoegbu E, Uloko AE, Diabetes Association of Nigeria (2011) National clinical guideline for diabetes management.

23. Yusuff KB, Obe O, Joseph BY (2008) Adherence to antidiabetic drug therapy and self management practices among type-2 diabetics in Nigeria. Pharm World Sci 30: 876-883.

24. Adisa R, Alutundu MB, Fakeye TO (2009) Factors contributing to nonadherence to oral hypoglycemic medications among ambulatory type 2 diabetes patients in Southwestern Nigeria. Pharm Pract 7: 163-169.

25. Desalu O, Salawu F, Jimoh A, Adekoya A, Busari O, et al. (2011) Diabetic foot care: Self reported knowledge and practice among patients attending three tertiary hospital in Nigeria. Ghana Med J 45: 60-65.

26. Taylor $O$ (2008) Affordability of medicines for patients with diabetes attending University of Nigeria teaching hospital (UNTH), Enugu: A minithesis submitted in partial fulfilment of the requirements for the degree of magister in public health in the school of public health in the faculty of community and health sciences.

27. World Health Organization (2005) Chronic disease and poverty in preventing chronic diseases: A vital investment: WHO global report. World Health Organization, Geneva, Switzerland.

28. Agbir MT, Adebowale TO, Audu MD, Goar SG, Puepet $\mathrm{FH}$, et al. (2010) Clinical correlates of depression among diabetics in Jos, Nigeria. J Med Tropics 12: 37-41.

29. Ijeh LL, Okorie U, Ejike C (2010) Obesity, metabolic syndrome and BMI-metabolic-risk sub-phenotypes: A study of an adult Nigerian population. Journal of Medicine and Medical Sciences 1: 254-260.

30. Ogbera A, Fasanmade O, Ohwovoriole A (2006) High costs, low awareness and a lack of care-the diabetic foot in Nigeria. Diabetes Voice 51: 30-32.

31. Nathan DM, Buse JB, Davidson MB, Ferrannini E, Holman RR, et al. (2009) Medical management of hyperglycemia in type 2 diabetes: A consensus algorithm for the initiation and adjustment of therapy a consensus statement of the American Diabetes Association and the European Association for the study of diabetes. Diabetes Care 32: 193-203.

32. Scain SF, Dos santos BL, Friedman R, Gross JL (2007) Type 2 diabetic patients attending a nurse educator have improved metabolic control. Diabetes Res Clin Pract 77: 399-404.

33. Norris SI, Lau J, Smith SJ, Schmid CH, Engelgau MM (2002) Self-management education for adults with type 2 diabetes: A meta-analysis of the effect on glycemic control. Diabetes Care 25: 1159-1171.

34. Eakin EG, Bull SS, Glasgow RE, Mason M (2002) Reaching those most in need: A review of diabetes self-management interventions in disadvantaged populations. Diabetes Metab Res Rev 18: 26-35.

35. Funnell MM, Brown TL, Childs BP, Haas LB, Hosey GM, et 
al. (2009) National standards for diabetes self-management education. Diabetes Care 33: s87-s94.

36. Clark M (2008) Diabetes self-management education: A review of published studies. Prim Care Diabetes 2: 113120.

37. Wattana C, Srisuphan W, Pothiban L, Upchurch SL (2007) Effects of a diabetes self-management program on glycemic control, coronary heart disease risk, and quality of life among Thai patients with type 2 diabetes. Nurs Health Sci 9: 135-141.

38. Gucciardi E, Chan VW-S, Manuel L, Sidani S (2013) A systematic literature review of diabetes self-management education features to improve diabetes education in women of Black African/Caribbean and Hispanic/Latin American ethnicity. Patient Educ Couns 92: 235-245.

39. Fan L, Sidani S (2009) Effectiveness of diabetes selfmanagement education intervention elements: A metaanalysis. Canadian J Diabetes 33: 18-26.

40. Mulcahy K, Maryniuk M, Peeples M, Peyrot M, Tomky D, et al. (2003) Diabetes self-management education core outcomes measures. Diabetes Educ 29: 768-770, 773-784, 787-788.

41. Keogh KM, White P, Hevey D, Mcgilloway S, Smith SM (2009) Family based interventions to improve outcomes in patients with type 2 diabetes mellitus. Cochrane Database Syst Rev 1: cd006382.

42. Samuel-hodge CD, Keyserling TC, Park S, Johnston LF, Gizlice Z, et al. (2009) A randomized trial of a church-based diabetes self-management program for African Americans with type 2 diabetes. Diabetes Educ 35: 439-454.

43. Partnership for Prevention (2009) Diabetes selfmanagement education (DSME): Establishing a communitybased DSME program for adults with type 2 diabetes to improve glycaemic control-an action guide. The community health promotion handbook: Action guides to improve community health. Washington, DC, USA.

44. Lorig K, González VM (2000) Community-based diabetes self-management education: Definition and case study. Diabetes Spectrum 13: 234-238.

45. Lorig K, Ritter PL, Villa FJ, Armas J (2009) Communitybased peer-led diabetes self management a randomized trial. Diabetes Educ 35: 641-651.

46. Balagopal P, Kamalamma N, Patel TG, Misra R (2008) A community-based diabetes prevention and management education program in a rural village in India. Diabetes Care 31: 1097-1104.
47. Butcher MK, Gilman J, Meszaros JF, Bjorsness D, Madison $M$, et al. (2006) Improving access to quality diabetes education in a rural state: The montana quality diabetes education initiative. Diabetes Educ 32: 963-967.

48. Rintala T-M, Jaatinen $P$, Paavilainen $E$, Astedt-kurki $P$ (2013) Interrelation between adult persons with diabetes and their family: A systematic review of the literature. J Fam Nurs 19: 3-28.

49. Armour T, Norris S, Jack L, Zhang X, Fisher L (2005) The effectiveness of family interventions in people with diabetes mellitus: A systematic review. Diabet Med 22: 1295-1305.

50. García-huidobro D, Bittner M, Brahm P, Puschel K (2011) Family intervention to control type 2 diabetes: A controlled clinical trial. Fam Pract 28: 4-11.

51. Polonsky WH, Earles J, Smith S, Pease DJ, Macmillan M, et al. (2003) Integrating medical management with diabetes self-management training a randomized control trial of the diabetes outpatient intensive treatment program. Diabetes Care 26: 3048-3053.

52. Emerson S (2006) Implementing diabetes self-management education in primary care. Diabetes Spectrum 19: 79-83.

53. Heinrich E, Schaper NC, De vries NK (2010) Selfmanagement interventions for type 2 diabetes: A systematic review. European Diabetes Nursing 7: 71-76.

54. Izquierdo RE, Knudson PE, Meyer S, Kearns J, Ploutzsnyder R, et al. (2003) A comparison of diabetes education administered through telemedicine versus in person. Diabetes Care 26: 1002-1007.

55. Moreno L, Dale SB, Chen AY, Magee CA (2009) Costs to medicare of the informatics for diabetes education and telemedicine (ideatel) home telemedicine demonstration findings from an independent evaluation. Diabetes Care 32: 1202-1204.

56. Piette JD, Weinberger M, Mcphee SJ, Mah CA, Kraemer FB, et al. (2000) Do automated calls with nurse follow-up improve self-care and glycemic control among vulnerable patients with diabetes? Am J Med 108: 20-27.

57. Sultan S, Mohan P (2009) MyDR: Improving the self-care process for Caribbean patients with diabetes through mobile learning. International Journal of Education and Development using Information and Communication Technologies, 5 . 